\section{COVID-19 and plastic use in dentistry}

Sir, in response to Ifrah Khan's Being mindful of the environment: Why does it matter to dental students?, ${ }^{1}$ we agree that the dental profession is a significant contributor to plastic usage and would also like to note the alarming increase of this during the COVID19 pandemic. While single-use PPE protects dental professionals against the virus as they continue to provide essential service to the public, the long-term impact of the disposal of these materials remains a concern for the environment.

To enhance their fluid and pathogen filtration properties, some enhanced PPE donned during Aerosol Generating Procedures (AGPs) (e.g. respirators) are made of materials consisting of higher numbers of plastic polymeric layers compared to basic PPE (e.g. surgical face masks). ${ }^{2}$ As more AGPs will likely need to be conducted with the gradual return of elective dental procedures, the use of enhanced PPE is expected to increase as well. The concern in this situation is whether waste services will be able to manage the disposal of these materials safely.

\section{'The long-term impact of the disposal of these} materials remains a concern for the environment'

The persistence and durability of plastic polymers make it challenging to break them down into components that can be safely released into the environment. The combustion of plastic polymers not only produces air pollutants, but leaves microplastic residues as well. ${ }^{3}$ If not managed appropriately, the release of these substances into the environment can damage the delicate balance of ecosystems and bring about catastrophic effects. While there are legislations and government directives in place to prevent this from happening, ${ }^{4}$ the threat of another wave of the pandemic and the precarious state of the current economy can pose significant strain to waste services and make it challenging for them to safely manage clinical plastic waste.

The WHO has warned that COVID-19 may become endemic within the population. ${ }^{5}$ Thus, the public and healthcare sector's demand for PPE will likely remain high for the foreseeable future. It is crucial that we explore alternatives to ensure that our use and disposal of PPE is sustainable so that we can minimise the damage to the environment. PR Chua, and JQ Teh, Glasgow

\section{References}

1. Khan I. Being mindful of the environment: Why does it matter to dental students? BDJ Student 2020; 27: 24-26.

2. Wibisono Y, Fadila C R, Saiful S, Bilad M R. Facile Approaches of Polymeric Face Masks Reuse and Reinforcements for Micro-Aerosol Droplets and Viruses Filtration: A Review. Polymers 2020; 12: 2516.

3. Ahmadifard A. Unmasking the hidden pandemic: sustainability in the setting of the COVID-19 pandemic. $\mathrm{Br}$ Dent J 2020; 229: 343-345

4. Moritz J M. Current legislation governing clinical waste disposal. J Hosp Infect 1995; 30: 521-530.

5. Brenza A. COVID-19 'May Never Go Away,' Warns the World Health Organisation [Internet]. Health.com. 2020 [cited 8 November 2020]. Available from: https://www. health.com/condition/infectious-diseases/coronavirus/ what-is-an-endemic-virus (Accessed April 2021).

https://doi.org/10.1038/s41406-021-0218-2

\section{Be strong you never know who you are inspiring}

Sir, I think we can all recall the horror of that day in March. I remember a few days prior to the dreaded day, I was booking my patient in for an 11 (UR1) tooth extraction due to his failing post and crown that kept falling out. Inevitably, resulting in a consequent poor prognosis. The plan was to adjust his existing partial denture to fit the gap left by his 11. I felt empathetic for my patient because losing a front tooth is no easy thing to do. And on top of that adjusting to this newly added component is no easy task to bear. But in the end, all that mattered is that this treatment option would solve my patient's disease, comfort, self-esteem and allow him to eat. I never thought this plan would be delayed because of a global pandemic, which would inevitably shut down society as we know it.

When lockdown began that was all I could think about... my poor patient struggling with his failing post and crown.

I wasn't the only one struggling with these negative thoughts.

In a cross-sectional study assessing the impact of COVID-19 pandemic on mental health and wellbeing on adults, the results showed that self-isolating before lockdown, increased feelings of isolation. Additionally, concerns regarding living with COVID-19, was linked with poorer mental health, wellbeing and quality of life. ${ }^{1}$ This is understandable. Our negative response to a global pandemic is a natural way of responding to a crisis. Adults are more attentive and influenced greater in perceiving negative influences in most psychological domains in comparison to positive information (negative bias). ${ }^{2}$

Interestingly this study found that perceived increased kindness, community connectedness and being an essential worker were associated with better mental health and wellbeing outcomes ${ }^{1}$. Kindness is defined as 'the quality of being friendly, generous and considerate. ${ }^{3}$ It is something we all need, to rise above the ashes which the flames of COVID-19 have created. It is a very simple act; we as dental professionals can easily follow. It all begins with being kind to yourself.

Self-care is a hot topic in society today, but this new phenomenon has existed before health systems were put in place. Nowadays, self-care is advocated by celebrities and companies consequently leading to the rise of the 'self-care aficionado'. During lockdown, I found that being kind to myself resulted in allowing myself to treat others better with more dignity and respect. This meant that I was more compassionate towards others and this led to me feeling happier. Research has studied how individuals felt after performing or observing acts of kindness daily for a week and found that performing these acts for just seven days can boost happiness. ${ }^{4}$

So, is this the secret to defeating the challenges we face, as dental professionals and inevitably as individuals, in today's tough society?

With all these virtual Zoom calls, banana bread and mask-covered individuals I can see how it can be hard to practice this philosophy when smiling at someone who isn't recognised behind the mask. However, there are so many ways that the power of positivity can be utilised during these tough times. Through gratitude.

It's a Thanksgiving tradition which the USA has embraced but it's a simple act which can have dramatic positive effects. By being thankful for what we have, can help shift our brain's focus in reaffirming that we are living a good life in spite of our 